\title{
The Conundrum of Work-Life Balance
}

\author{
Libby V. Morris ${ }^{1}$
}

Published online: 31 May 2019

(C) Springer Nature B.V. 2019

Recently, a faculty colleague asked me to visit her graduate seminar in student affairs to discuss the role of provost (in which I am now serving my second term as interim, but that's a story for another day!). I began my remarks with a brief overview of the University's organizational chart and then described various formal roles and responsibilities, after which the students enthusiastically launched into questions. The question that caught me off-guard, once again, was one I have heard several times this year. How did I handle work-life balance, and what is my advice? They thought I had it all figured out! Well, words just popped out of my mouth, that is, I haven't known anything about work-life balance in 30 years! I am afraid that I sounded a little exasperated with the question and then said something like "I am probably not the best person to ask."

Upon regaining (I hope) my composure, I did encourage those graduate students who were on the brink of their professional careers to give this anticipated or experienced dilemma some dedicated attention. I tried to encourage them to develop strategies to avoid burnout and the frustration that comes from sensing a lack of balance. I also tried to explain my perception that balance is more than individual mastery of the environment; it is a part of a push-and-pull from actors and requirements and expectations ever whirling in our minds and in our realities. Often the family experiences the greatest reverberations from even the smallest shifts in "balance." Maybe the word "life" could be substituted with the hyphenated words of "work-family" or "work-personal" or "work-social." Interrogating the term "work-life balance" is part of the challenge.

Continuing the self-indulgence of reflection, occasionally I do think about all of the books, movies, and socializing with friends that I have never quite been able to work into my schedule. The "balance activities" were always more ad hoc... a day off here, a vacation there, a few sporting events, and so on. So, there was some fun along the way, but it was generally inserted here and there and not nearly regularly enough. I guess the balance piece is the challenge for me.

So, with an inability to fix the past (at least in the career dimension), I began thinking aloud with the graduate students about "work-life balance." True to form, I did not think about "life," but rather "work." I explained that work is a large part of who I am; I cannot put it on

Libby V. Morris

lvmorris@uga.edu 
and take it off like a jacket. Thoughts about work responsibilities and tasks, those travel with me day and night, wherever I am. When I am not at "work," I am involved with work-an email or phone call or letters and paperwork. What person in the academy does not read scholarly and popular press articles when away? What professional does not finish a project from the comfort of a favorite chair at home? Life and work may become compatible and comingled.

Work-life balance, however, poses a distinct set of challenges across individuals, groups, and occupational sectors; and professionals generally have an advantage of education and the privilege of a job that means more than economic security. Thus, "work-life balance" should be viewed through multiple lenses. A career, unlike many jobs, allows one to have friends at work, where tenures may be long and friendships with colleagues established over years. I have had that good fortune at the University of Georgia.

In retrospect, the term "work-life balance" seems dichotomous; yet I think the hyphen is supposed to suggest a continuum. However, whenever I hear the words, it seems the challenge is posed as an either-or: either you are enjoying work or you are enjoying life. Perhaps worklife is the wrong phrase; maybe the focus and term should be personal balance. How does one achieve personal balance and extract meaning and joy from a wide range of roles - worker, partner, mother, friend, athlete, volunteer, and so on? How do we embrace the challenges of role conflict and precedence? Roles and priorities shift in importance over time.

I think it is time to move away from the tired and impossible term "work-life balance," which leaves many people feeling discouraged and failing. A more productive conversation might emerge from a discussion of "balance" and a heightened awareness that balance is not the same for everyone. Balance may be quite individualistic and thus the failure of broad strategies as advice. In full transparency, I am writing this while on vacation at the beach. Is the balance right? Probably not, but I chose to find joy in the different scenery and a family that extends to me the peace of understanding.

There is not perfect equilibrium, and even the term work-life balance must be interpreted against a backdrop of gender, education, economic status, and other social issues. Much of the popular advice on work-life balance has focused on women and the challenges of child-rearing or other care-taking roles and work. Other articles assume the privilege of independence in decision-making about work and ignore the challenge of work as absolute economic necessity_paycheck to paycheck. Company or organizational norms also affect an individual's definition of work and commitment to hours, place, and tasks. Some still think they can "do it all." Language molds the creation of reality and the perception of reality and is important to framing an issue.

As we interact with each other and those at the beginning of their professional careers, what do they really want to know when they ask the "work-life-balance" question? Can we help redefine the question? Are answers filled with "one size fits all" strategies actually very helpful? You know, those that advise setting boundaries, controlling your schedule, and so forth. Is the question actually, what means the most in life and in a career? How do we know? How do we decide? Can we prioritize and find meaning in the journey? For me the seesaw is rarely parallel to the ground.

Publisher's Note Springer Nature remains neutral with regard to jurisdictional claims in published maps and institutional affiliations. 